\title{
PARA uma CULTURA INTEGRAL: O CONTRIBUTO DA HISTÓRIA DA CIÊNCIA
}

\author{
António Manuel Nunes dos Santos \\ Faculdade de Ciências e Tecnologia, Universidade Nova de Lisboa \\ amans@fct.unl.pt
}

Na hora da jubilação, ao Rui Namorado Rosa com amizade e a estima de sempre

\begin{abstract}
The Contribution of the History of Science toward an Integral Culture - We presently inhabit a world where the successes of science and its technological applications inspire admiration amongst our contemporaries. Nonetheless, there remains a sentiment of deep ambivalence before such successes and a gap between science (and its prodigious developments) and society in general which is still not scientifically literate. The transmission of theoretical, fundamental, and applied science is still subject to a centripetal diffusion of knowledge that is peer-driven, self-isolating, and often largely unaware of the intrinsic cultural value of its patrimony.

In this paper emphasis will be given to the values of dialogue and conciliation with a view to bridging the gap between the growth of knowledge - veritable mirror of human endeavour and creativity - and the erroneous view that such knowledge must forever remain inaccessible to the uninitiated.

The history of science (along with the philosophy of science) are fields of inquiry which help to establish dialogue between knowledge domains, to develop the researcher's critical thinking, to define significant pedagogical concepts, and to surpass the shattered whole still characterising the ensemble of scientific knowledge in favour of an inter-and multidisciplinary approach. The historian and philosopher of science crosses the threshold of the laboratory to study the scientific labour there carried out, follows controversies and subverts all superficial consensus, to give primacy to the arena of scientific memory of which we are all direct and indirect heirs, where intellectual and conceptual perspectives are considered in their economic, social, political, and ethical context as they together foment cultural progress.
\end{abstract}

$\mathrm{V}_{\mathrm{i}}$ ivemos num mundo em que o sucesso da ciência e das suas aplicações técnicas provoca admiração nos nossos contemporâneos; contudo, continua a haver um sentimento de ambivalência profunda e um hiato entre a ciência (em vertiginoso desenvolvimento) e uma sociedade que deveria ser cientificamente culta. A transmissão da ciência pura, fundamental e aplicada é ainda sujeita a uma difusão centrípeta do saber, entre pares, isolada e até muitas vezes alheada do valor cultural do seu património intrínseco.

Neste artigo dá-se ênfase ao diálogo e à conciliação entre o desenvolvimento do conhecimento, espelho vivo da aventura e criatividade humanas, e a mistificada inacessibilidade dos saberes pelos profanos.

A História da Ciência (e a Filosofia da Ciência) ajuda(m) a criar pontes nesse diálogo, a desenvolver o espírito crítico do investigador, a clarificar as ideias do pedagogo, a romper a visão fragmentada das áreas científicas em favor de uma abordagem inter e multidisciplinar, a entrar nos Laboratórios e estudar o "trabalho" científico, a seguir controvérsias e a derrubar consensos, dando primazia à arena da memória científica de que todos somos herdeiros, em que as perspectivas intelectuais e cognitivas se encontram inseridas num contexto económico, social, político e ético do progresso das sociedades.

As ilusões nunca são perdidas. Elas significam o que há de meIhor na vida dos homens e dos povos. (Bento de Jesus Caraça)

The goal of education is not mastery of subject matter, but of one's person. (David Orr)

Estudar é para ele [o estudante] uma necessidade exterior, que lhe é imposta. (Ortega y Gasset)

Há quarenta anos, no livro The Devil in Modern Philosophy, Ernest Gellner afirmava: "Se se reunissem todos os filósofos americanos num único lugar e se se deixasse cair uma bomba atómica sobre eles, a sociedade americana não ficaria minimamente afectada. Ninguém registaria a menor diferença nem haveria qualquer lacuna, nenhum vácuo na economia, a precisar de reparação" [1]. Numa altura dominada pela expansão rápida do conhecimento, numa cultura moderna secular com raízes profundas na ciência, num mundo dominado por uma sociedade industrial, por uma aplicação e utilização tecnológica feroz e sedutora que caracteriza o desenvolvimento das nações, esta afirmação, esta ideia de aniquilação, de rendição do pensamento, mesmo que atenuada por apenas ser uma afirmação escrita, não concretizada mas não complacente no ver e sentir as "coisas”, além de chocante - os filósofos representam de certo modo o inquiridor perpétuo - evidencia que todos os aspectos desta cultura moderna incluindo as formas do criticismo activo, dos profundos comprometimentos intelectuais e convicções são hoje em dia subordinados ao universo económico impetuoso e dominante que subjuga o homem-comum, e, tudo o resto, é de certo modo invisível. Este universo, além de subjugar o homem, amarra-o, controla-o, aprisiona-o e até mesmo “aniquila-o" já que ele não tem qualquer controle ou poder para agir nesse domínio. Aparentemente, o que conta são os "negócios" e a "utilidade" da vida e assiste-se à indiferença generalizada e ao silêncio 
cúmplice face à injustiça e cega preservação da miséria, à exclusão social e ao aumento contínuo da riqueza inaudita e desmesurável. É precisamente isto que constitui, no dizer de Marcuse [2], "the most impartial indictment even if they are not the raison d'être of this society but only its by-product: its sweeping rationality, which propels efficiency and growth, is itself irrational”.

E nesta jornada, nesta errância que é a nossa, que já não alimenta o que de mais nobre tem o valor humano, o savoir-vivre ensemble, a prática do bem-estar comum, da responsibilidade por si e pelo Outro, do auxílio mútuo, da inter-ajuda, de exigir o cumprimento da responsabilidade do Estado pelas funções sociais que lhe são imputáveis, como explicar que o cidadão tenha consciência que vive numa sociedade racional (científica) e avançada? Perante a apatia do cidadão, face à manipulação que subverte a função cognitiva, a sua renúncia à militância pelos seus ideais e até mesmo à revolta perante o despudor e o desnorte daqueles que efectivamente detêm o poder político e económico, como explicar o fascínio que sente pelas aplicações tecnológicas que muitas vezes não consegue compreender mas que satisfaz os seus prazeres primários e utilitários e suposta livre escolha?

Como se passa de um mundo de objectivação científica e tecnológica tão activa e consciente e adormecer, senão esquecer, o mundo dos valores? Na verdade, os valores e os ideais constituintes da nossa humanidade, altamente dignificantes - moral e espiritualmente - contam menos neste mundo das vivências - assuntos "reais" da vida - talvez por serem não-objectivos e consequentemente não contabilizáveis. Hoje, para os Estados, o ser humano é um custo (e até um ser descartável!) - facto que propagandeia e dissemina - e que fatalmente o homem “médio” assimila facilmente. Como contrariar isto e, simultaneamente, dar consciência ao ser humano da possibilidade de se construir ele-mesmo? Qual é o papel da educação e da universidade - como missão - no contributo desse direito inato de cada um se realizar plenamente e participar activamente na formação do seu próprio avenir, ou melhor, no seu devenir? Ortega y Gasset - um dos meus referenciais intelectuais desde a juventude (há os que ficam como âncoras) - num magnífico texto da sua obra Misión de la Universidad, intitulado "Lo que la Universidad tiene que ser «primero", la universidad, la profesión y la ciencia”, indica-nos: "hay que hacer del hombre medio, ante todo, un hombre culto situarlo a la altura de los tiempos” [3]. O autor vai até mais longe do que apenas situá-lo à altura do tempo, mencionando no parágrafo seguinte, “y muy especialmente a la altura de las ideas del tiempo”.

Como formar este homem consciente das ideias do seu tempo? Como despertar a "alma colectiva das massas", para parafrasear um outro dos meus referenciais intelectuais Bento de Jesus Caraça - para essa tarefa? O homem culto é, para o referido autor, aquele que 1) tem consciência da sua posição no Cosmo e, em particular, na sociedade a que pertence; 2) tem consciência da sua personalidade e da dignidade que é inerente à existência como ser humano; e 3) faz do aperfeiçoamento do seu ser interior a preocupação máxima e fim último da vida [4]. Como preservar este grau de saber, mas mais do que preservá-lo, como praticá-lo?

Durante as últimas décadas, e hoje ainda, era e é suposto a escola fornecer conhecimento específico de modo a que o diplomado possa ser inserido no mercado de trabalho com direito a um emprego de qualificação correspondente à sua “formação". Fez-se disso a prioridade primeira e última da Escola: a aquisição de competências, afirmam responsáveis políticos, docentes e discentes, todo o sistema, é dever a ser cumprido. Se a educação, porém, - e este é um olhar íntimo e pessoal - tiver por objectivo a realização completa do homem, o desabrochamento completo do homem em toda a sua riqueza e complexidade das suas expressões e comprometimentos, das suas aspirações e concretização de ideias, dos laços que tece como indivíduo e na multiplicidade das suas partilhas, se tiver em consideração que o homem é essencialmente um ser criativo, inatamente solidário, um ser livre, consciente das suas escolhas e um ser em metamorfose contínua, perpetuamente contínua, então para formar este homem completo - um ser que sabe e deseja aprender a ser - a educação não pode ser temporal (o período escolar) e com o intuito apenas em transmitir conhecimento fragmentado e especializado.

A minha utopia é que a Escola seja impulso para o indíviduo se tornar criador de sonhos ("o sonho comanda a vida", como diria António Gedeão) e demolidor de dogmas, que lhe permita expandir os seus conhecimentos e fazer deles parte integrante da sua cultura e simultaneamente estender as suas fronteiras - a do sentir e a do pensar, em suma, a do viver em plenitude - até ao infinito, comandado sempre pela sua humanidade assente em valores éticos, de integridade e de justiça social.

Como pode então a História de Ciência - mormente a história das ideias científicas - contribuir para uma cultura integral? Escrever História tem em geral facetas duplas: escrever sobre e escrever por quem; narrar sobre e reconstruir o quê; descrever sobre e interpretar algo. Esta relação dupla envolve uma interacção entre a interpretação dos factos e o intérprete, reversibilidade que, embora não necessariamente viciada, acontece subtilmente na nossa compreensão: "Into every act of knowing there enters a passionate contribution of the person knowing what is being known and that this coefficient is no mere imperfection but a vital component of his knowledge” [5].

Por outro lado, se se considerar a racionalidade como critério do pensamento humano e o principal propósito da ciência descobrir coisas novas, centrada essencialmente no presente e com previsibilidade no futuro, que interesse tem a história e a reconstrução lógica dos acontecimentos e das ideias e explicações (teorias) do passado? Os livros de textos científicos, fonte de formação dos cientistas, mutilam a história da ciência e até a imagem de uma determinada área da ciência; apresentam o registo do conhecimento de modo objectivo e acumulativo, raramente evidenciam as controvérsias, confinam-se ao contexto de explicação e de 
aplicação e legitimam a crença que o cientista é um master builder, sempre com sucesso, seguindo um processo linear de assentar as suas ideias sobre a dos gigantes do passado, permitindo-lhe ver mais além do que os seus predecessores. Esses mesmos livros de texto têm por objectivo explicar factos, proclamando sempre as "verdades científicas" de modo a impedir que se gerem dúvidas e inquietações, que são precisamente os entrelaços fecundos e necessários ao progresso científico, e que asseguram a verdadeira paixão pelo conhecimento. Associado a isto temos ainda a visão do knowing teacher que, segundo Mortimer Adler no seu artigo "The Professor or the Dialogue”, ajusta o aluno a uma assimilação e a uma proficiência em memória verbal, ao que designa learning by instruction [6].

Nesta perspectiva, a educação científica é estreita e rigorosa, exclui alternativas e sobretudo dá ênfase, senão a uma única visão, à corrente de compreensão vigente da comunidade científica - as ideias científicas, as teorias, exigem consenso da comunidade científica e a ciência, actualmente, embora pracitada por indivíduos, é um empreendimento em grupo -, uma compreensão que é facilmente aceite de modo acrítico, muitas vezes sem necessidade de reflexão sobre os conceitos, dado o sucesso que a teoria apresenta na resolução de muitos problemas.

Ora, a história da ciência, na sua vertente de evolução das ideias científicas, mostra que a ciência é um processo por demais complexo para ser constituído apenas por regras lógicas, que possui períodos de crise que conduzem a novas regras - novos paradigmas, em termos kuhnianos - que permitem o desenvolvimento de novos modelos explicativos não só dos fenómenos que violam as regras anteriores bem como dos fenómenos que eram logicamente explicadas por essas mesmas regras. Em suma, temos uma nova visão explicativa de todos os fenómenos.

Esta abordagem de reconstrução do passado ajusta-se fortemente a uma outra visão do professor, a do inquiring teacher, bem como de um novo modelo de aprendizagem - learning by discovery. Neste processo de (re)descoberta, de (re)criação toma-se consciência que o modelo de conhecimento é transformador e controverso em vez de narrativo e sempre consensual e que o facto experimental, tantas vezes considerado objectivo, e a sua descrição e explicação dependem já de uma articulação, de um vínculo à teoria assimilada pelo cientista. Einstein estava muito consciente disso. Heisenberg, numa conferência realizada em 24 de Abril de 1973, em Washington D. C., num simpósio patrocinado pela Smithsonian Institution e pela National Academy of Sciences, em que comenta as três influências mais importantes da tradição na ciência - na selecção dos problemas, no método e nos conceitos - ao abordar o enfoque empírico da ciência, ou seja, à abordagem em que se deduzem os modelos e as relações matemáticas a partir de resultados empíricos, relata-nos:

If this were the whole truth, we should, when entering into a new field, introduce only such quantities as can directly be observed, and formulate natural laws only by means of these quantities. When I was a young man, I believed that this was just the philosophy which Einstein had followed in his theory of relativity. Therefore I tried to take a corresponding step in quantum theory by introducing the matrices. But when I later asked Einstein about it, he answered, 'This may have been my philosophy, but it is nonsense all the same. It is never possible to introduce only observable quantities in a theory. It is the theory which decides what can be observed' [7].

O que Einstein pretendia dizer é que não se pode separar a observação das relações matemáticas e dos conceitos teóricos já adquiridos e que fazem parte da estrutura mental do observador.

Esta interligação não é evidenciada na educação científica. Antes, pelo contrário, como doutrinação ideológica, o que é realmente transmitido ao jovem praticante de ciência são teorias científicas sedimentadas através das aplicações práticas e não pela interligação "exemplo-regras abstractas”. Muitas vezes tal doutrinação induz à memorização dos conceitos, a uma domesticação do pensamento, que cria grilhões difíceis de ultrapassar no trajecto criativo dos praticantes da ciência. Além disso, tal prédica pode até ter consequências mais graves. A proficiência em memória verbalizada instiga não só uma indisponibilidade para saborear o conhecimento mas sobretudo propicia o esquecimento, ou pior ainda, incita a uma disponibilidade para facilmente se libertar dele. $\mathrm{O}$ deitar fora, com muito à-vontade, o conhecimento adquirido durante o período de aprendizagem e mormente após a avaliação - os exames - é sem dúvida perturbador. Muito provavelmente, os iniciados fazem-no porque no processo de transmissão - no aprender e no ensinar - não se foca o modo como o conhecimento é produzido, donde provém, dando-se ênfase à utilidade, à prática desse conhecimento, subalternizando-se assim a compreensão. Há pouco uso de fontes primárias que auxiliariam a "apreender” como uma determinada área científica evoluiu, um trajecto que é um processo inacabado; muito do saber, ainda hoje, é dado em pacotes de “conhecimento acabado”, dogmaticamente afirmado, pacotes de conhecimento que devem ser aplicados em alguns exemplos práticos.

Se há mudança na estrutura da universidade, hoje mais consciente da dicotomia ensino-investigação, essa mudança é só parcial dado que se encontra muito direccionada apenas ao docente. Mas para o aluno, qual é o valor do conhecimento? Se ele não souber integrar o conhecimento - obstinação da sua paixão - na sua própria cultura e não fazer dele o motor da sua transformação como ser humano, pode sem dúvida ter algum prazer intelectual, mas seguramente não engrandece a sua sensibilidade espiritual nem o alerta para a responsabilidade social como cientista e como cidadão para as consequências da utilização do seu conhecimento. Esse conhecimento de per si, isolado, não reflectido, pode até, em certa medida, outorgar-lhe uma falsa convicção de superioridade e alguma arrogância face aos profanos - desconhecedores das teorias científicas e 
técnicas - mas não o integra na plena cultura do seu tempo, que lhe permite descobrir as diferenças e as injustiças do mundo em que vive e no qual se tem de inserir. É também aqui que a História da Ciência, numa dimensão mais abrangente de narrativa, de story-telling, pode transmitir, de modo mais aliciante e simplificado, mas não menos correcto, não só a praxis dessa actividade humana que é a ciência, mas sobretudo alargar as fronteiras dos cidadãos para uma melhor compreensão do que se passa na arena fechada dos laboratórios e das instituições onde se constrói o conhecimento e alertar o cidadão-comum para as implicações e consequências da (má) utilização da ciência.

O conhecimento científico é hoje, como nunca, parte integrante e indispensável da cultura. Vivemos numa sociedade cada vez mais rapidamente tocada pelo progresso científico e evolução tecnológica, contudo, o homem alheado ou que presume não ser capaz de compreender o que se passa nas áreas científicas, mesmo que superficialmente, é, de certo modo, cúmplice das barbáries que se cometem nesta Idade científico-tecnológica. A ciência, isolada do meio social, pode tornar-se não só demasiado poderosa, ambiciosa e dinâmica mas também demasiado perigosa para ser deixada a si própria.

Ao cidadão, e ao cientista em particular, cabe-lhe uma grande responsabilidade quanto à edificação do futuro. No que respeita à inter-relação responsabilidade-ética de um cientista, Primo Levi, o químico, escritor e sobrevivente de Auschwitz, num magnífico texto intitulado em inglês "Hatching the Cobra”, coligido na sua obra Racconti e Saggi, conta a história de Fálaris, o tirano de Agrigento (Séc. VI, A.C.) e do seu cruel artífice, Perilo. Este, fascinado para mostrar a sua perícia, constrói um touro, a pedido do tirano, em que um homem, colocado no seu interior, "mugiria” quando se acendesse lume debaixo dele, não se dando conta que ele próprio seria a primeira vítima. Primo Levi alerta assim o cientista para não se deixar cair na tentação da resolução de problemas sem saber a finalidade "to which your work is directed”. E, consciente da enorme sedução do cientista em abraçar instintiva e inegavelmente uma questão ou problema do qual não sabe a resposta, conclui:

Whether you are a believer or not, whether a 'patriot' or not, if you are given a choice do not let yourself be seduced by material or intellectual interests, but choose from the field that which may render less painful and less dangerous the journey of your contemporaries, and of those who come after you. Don't hide behind the hypocrisy of neu- tral science; you are educated enough to be able to evaluate whether from the egg you are hatching will issue a dove or a cobra or a chimera or perhaps nothing at all. As for basic research, it can and must continue: if we were to abandon it, we would betray our nature and our nobility as 'thinking reeds,' and the human species would no longer have any reason to exist [8].

Saibamos nós termos uma verdadeira percepção da aplicação do trabalho científico em que estejamos envolvidos, um sentido de responsabilidade ímpar de modo a sermos dignos de respeito pelas gerações futuras.

\section{BIBLIOGRAFIA}

[1] E. Gellner, The Devil in Modern Philosophy, Routledge \& Kegan Paul, 1974

[2] H. Marcuse, One Dimensional Man, Studies in the Ideology of Advanced Industrial Society, Boston: Beacon Press, 1964, p. xiii

[3] J. Ortega y Gasset, Misión de la Universidad y otros ensayos sobre educación y pedagogia, Alianza Editorial/Revista de Occidente, 1930, p.53

[4] B. de J. Caraça, “A cultura integral do indivíduo, Problema central do nosso tempo”, Conferência proferida na Universidade Popular Portuguesa, 25 de Maio de 1933, in Cultura e Emancipação (1929-1933), Obra integral de Bento de Jesus Caraça, Edição Crítica, Campo das Letras, 2002, pp.97-128

[5] M. Polanyi, Personal Knowledge, Towards a Post-Critical Philosophy, The University of Chicago Press, 1958, p. xiv

[6] M.J. Adler, “The Professor or the Dialogue,” The Mortimer J. Adler Archive, Cross Current Lecture of the Year (1958-59), http://radicalacademy.com/adler_the \%20professor. htm (acedido a 28/05/2014)

[7] W. Heisenberg, "Tradition in Science, Science and Public Affairs”, Bulletin of the Atomic Scientists vol. 29 (1973), pp.4-10

[8] P. Levi, "Hatching the Cobra”, in The Mirror Maker, trad. Raymond Rosenthal, London: Abacus, 2002, p. 214.

\section{BIBLIOGRAFIA COMPLEMENTAR}

J. Ortega y Gasset, “Sobre o estudar e o estudante”, in H. Arendt, E. Weil, B. Russell, J. Ortega y Gasset, Quatro textos excêntricos, Olga Pombo (pref. e trad.), Relógio d’Água, 2000, pp.87-103

D. Orr, What is Education for?, in The Learning Revolution, In Context (IC \# 27), Winter, Boston: Beacon Press, 1991, p.52

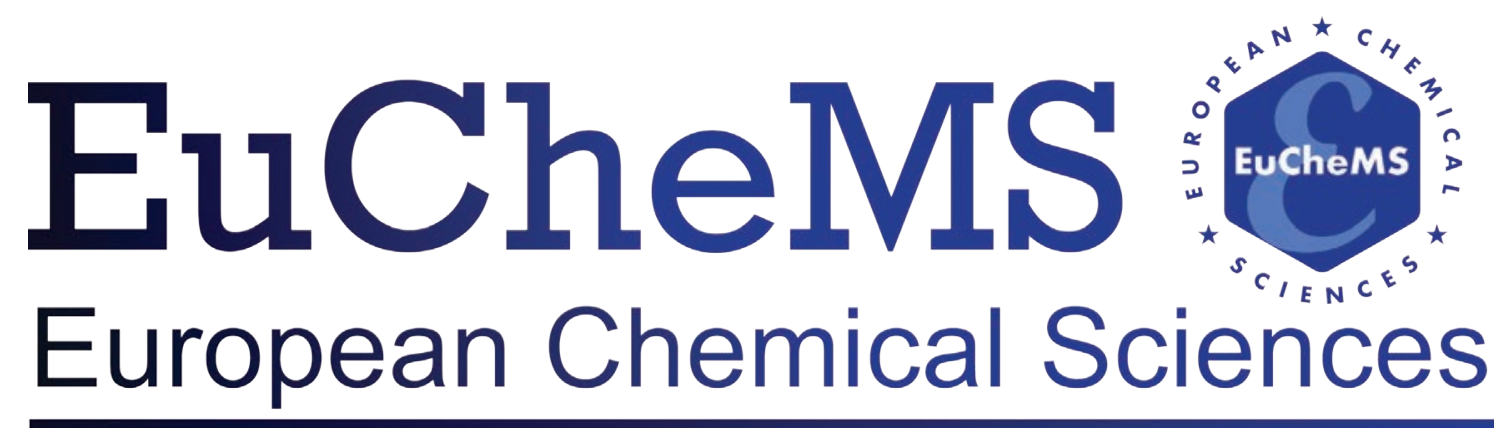

